\title{
A Literature Review of Foreign Studies on the Impact of CALL on Second Language Acquisition from 2015
}

\author{
Qiuxin Zhang ${ }^{1}$ \\ ${ }^{1}$ Lanzhou Jiaotong University, School of Foreign Language, Anning West Road, Anning District 88, China \\ Correspondence: Qiuxin Zhang, Lanzhou Jiaotong University, School of Foreign Language, Anning West Road, \\ Anning District 88, China.
}

Received: March 14, 2021

Accepted: May 14, 2021

Online Published: May 20, 2021

doi: 10.5539/elt.v14n6p76

URL: https://doi.org/10.5539/elt.v14n6p76

\begin{abstract}
With the rapid development of economy and technology, more and more fields are combined with electronic intelligence and artificial intelligence, and language teaching is no exception. As a research hot issue, computer-assisted language learning (CALL) has attracted more and more people's attention. Based on computer-aided technology, teachers can not only provide students with rich language input, but also improve classroom efficiency. However, there are still some problems in this technology. This paper reviews some empirical studies on the impact of computer-assisted language teaching from 2015 and reveals the relevant progress and shortcomings of foreign researches in terms of six aspects from the perspective of language teaching, in order to provide some enlightenment for future research.
\end{abstract}

Keywords: computer-assisted language teaching, SFL, English teaching and learning

\section{Introduction}

In the past few decades, due to the popularization of scientific knowledge and technology, more and more people have access to online resources, which means that even the children in the poorest areas may also be exposed to fresh knowledge and the most advanced ideas. Undoubtedly, it plays an important role in eliminating educational injustice. On the other hand, because of the development of science and technology, and the economy, people can get access to language learning websites, software, and even equipment, so CALL has become an important part of language teaching. CALL has become an indispensable auxiliary tool in English classrooms, even in all classes.

Through the Internet, computers, or projectors, teachers and students can get the latest information from all over the world. For English, such a communicative tool subject, broadening our horizons, understanding the customs, habits and cultural development behind the target country cannot lose the help of CALL.

The use of multimedia technology in English classrooms can not only easily solve the problems of traditional teaching modes, but also significantly improve the enthusiasm of students. (Crystal, 1997) Compared with the traditional teaching mode, its advantage is self-evident. It breaks the traditional teaching mode based on teachers and classroom indoctrination for thousands of years, changes the situation of high labor intensity and low learning efficiency, realizes multi-level development and reasonable allocation, and realizes the scientific, industrialized, and efficient education. (Zhang Hua, 2002) In 2004, the Ministry of Education of the People's Republic of China issued the Requirements for College English Teaching that "the advanced information technology should be used to promote English teaching based on computer and network". Therefore, based on CALL technology, it is necessary to study and discuss the ability of students in all aspects.

In order to describe the current situation of foreign researches as comprehensively and deeply as possible, find out the shortcomings of the researches, and provide suggestions for future researches and development, this study uses "the effect of CALL", "CALL", "Computer-assisted language teaching" as the keywords to search in CNKI and Baidu academic, the time set for the empirical researches from 2015 to now, initially screened out more than 30 related works of literature, and then screened out the literatures that have little relationship with this research after the artificial secondary screening, and finally determined the research materials as 15 articles, and carried out a comprehensive study. 
On the basis of intensive reading, this paper classifies the selected literature according to pronunciation, vocabulary, listening, reading, writing, and overall acquisition, so as to sort out the selected literature according to the research purpose.

Based on the previous studies, this paper discusses the empirical researches on this aspect in foreign countries in the past five years, aiming to confirm the role of CALL in promoting students' interest and learning initiation, as well as its role in promoting students' English skills, and expounds the current situation and development trend of CALL, so as to put forward suggestions.

\section{Literature Review}

\subsection{The Development of Concept}

As early as 1997, computer-assisted language learning was defined by levy as "the search for and study of applications of the computer in language teaching and learning". Since the 1960s, computers have been used in language teaching. (Mozhgan Sedaghatkar, 2018) After more than 20 years of development, with the popularity of networks and computers, CALL has become inseparable and closely related to foreign language teaching.

In fact, before the advent of CALL, it was mostly referred to as computer-assisted language instruction (CALI). However, as more and more people believed that language teaching activities should be student-centered rather than teacher-centered, CALI seemed to be a teacher-centered teaching method. Therefore, CALL began to replace CALI in the early 1980s. (Davies \& hewer 2011, p. 3) it is now incorporated into the names of the growing number of professional associations worldwide. (Nancy Anashia Ong'onda \& Mary Nguvi Muindi, 2016).

Jarf (2005) mentioned that CALL is a method of language teaching and learning, in which computer technology is regarded as an aid to the demonstration, reinforcement, and evaluation of the materials to be learned. On this basis, Richards and Schmidt (2010) defined it as "the use of computers in the teaching or learning of a second or foreign language". Such a simple and easy to understand definition has been used up to now. In line with their views, Khoshsima and Mozakka (2017) proposed that CALL is an approach to language teaching and learning in which computer technology is used to present, practice, reinforce, and assess learning materials. In 2017, Naimeh elaborated on other tools included in CALL: "CALL refers to a variety of technology uses for language learning including CD-ROMs containing interactive multimedia and other language exercises, electronic reference materials such as online dictionaries and grammar checkers, and electronic communication in the target language through email, blogs, and wikis." Therefore, we can know that CALL in the narrow sense refers to the use of computers, projectors and other auxiliary means in the classroom for foreign language teaching activities; in a broad sense, it refers to the use of interactive media to assist language teaching and learning, improve language learning efficiency, and comprehensively develop students' comprehensive ability of language use. Therefore, the emergence of computers as an aid in the language classroom has been the most significant landmark in recent language teaching methodologies. (Mozhgan Sedaghatkar, 2018, p. 231)

\subsection{The Effect of CALL}

Based on the empirical studies collected in recent years on the effects of CALL on second language learners' learning, the author divided them into six sections according to the subjects of the study: phonetics, vocabulary, listening, reading, writing, and the effects of CALL on the overall acquisition effect.

\subsubsection{Phonetics}

Pronunciation plays a crucial role in the development of pragmatic competence, and that pronunciation errors can cause pragmatic misunderstanding. (Pennington \& Zegarac, 1998)

Computer-assisted pronunciation training (CAPT) is one of the courses of English pronunciation-assisted teaching. CAPT has been found to be a great aid for teachers, especially for non-native teachers of the target language. (Nancy Anassia Ong'onda \& Mary Nguvi Muindi, 2016, p. 2) through the use of Capt, Dr. Nancy Anashia Ong'onda and Mary Nguvi Muindi believe that the use of CALL to learn a language is very instrumental since CAPT systems can provide language learners an authentic and native-like environment to learn English, therefore, their study used CAPT to do the empirical studies. CAPT systems make use of methods such as speech recognition, speaker normalization, and signal parameterization to present visible comparisons between students' attempts and the model. Through these traces, students can compare and get immediate feedback on their pronunciation using visual graphs. (Celce-Murcia, Brinton, Goodwin, \& Grinner, 2011)

Through the comparison between the control group and the experimental group, the conclusion is that CAPT program has a better function in teaching and learning English vowels and consonants. The scores of pronunciation and fluency in the experimental group were significantly higher, and it could play a certain role in the self-study of 
learners' pronunciation. The author also thinks that CALL and CAPT, in particular, should become indispensable and never be replaced by a teacher.

After data analysis by Fereshteh Rahnavard and Davood Mashhadi Heidar (2017), they found that CALL technology has a positive impact on students' pronunciation ability, and the pronunciation level of experimental group students is significantly improved compared with that of control group students.

These two new studies on the effects of CALL on phonological acquisition both show that CAPT has a positive effect on facilitating students' learning of pronunciation, generally in terms of pronunciation accuracy and fluency compared to the control group.

\subsubsection{Vocabulary}

In the field of foreign language teaching, vocabulary memory and mastery have always been one of the most concerned topics of teachers and scholars. Because "One indispensable factor in learning a second language is the amount of vocabulary one possesses, as vocabulary forms the biggest part of the meaning of any language" (McCarthy, 1988).

Mozhgan Sedaghatkar (2017) believed that the emergence of computers as an aid in the language classroom has been the most significant landmark. In order to explore whether computer-assisted language learning can help teachers simplify their role in the classroom, help them reduce the burden of memorizing words, and tap the potential of students. Through the pre-test, post-test, and questionnaire surveys, he got the results. The analysis data showed that the use of CALL had a positive impact on vocabulary learning, which was manifested as significantly enhancing students' immediate and delayed retention; students had a positive attitude towards CALL.

Nejati, Jahangiri, and Salehi (2018) believe that traditional vocabulary teaching cannot bring optimal vocabulary learning results. The introduction of CALL provides a convenient learning environment for learners and increases the learning motivation and effective multimedia content. Moreover, it can help learners study language individually at their own pace in a motivating atmosphere with a high level of interactivity. (Cellat, 2008) The results show that computers can provide language learners with major advantages, improve their motivation level, timely feedback, and correct students' errors, and such errors can only be seen by the students themselves, thus slowing down the students' psychological pressure, contributing to a low-affective-filter environment that facilitates language learning; (Krashen, 1982) In addition, it helps to strengthen group activities and teach personalized teaching, which is rare and difficult to achieve in a traditional classroom.

The results of the two studies showed that CALL can reduce students' stress in vocabulary memorization, create a relaxed and pleasant learning atmosphere, and provide good conditions for students' independent learning. The researchers also found that CALL enables students to learn in a low-affective-filter environment, which is a good way for some students with learning anxiety, or excessive psychological stress.

\subsubsection{Listening}

With the rapid development of CALL, its subordinate branches are also widely concerned by people. Among them, MCALL (Multimedia Assisted Language Learning) has opened up a new idea and vision for the popularization of modern science and technology into the classroom. In order to better reveal its teaching significance, Abbasian and Movahedfar (2016) took intermediate English learners as the research objects to explore its influence on listening comprehension. The study found that MCALL had a significant effect on the improvement of listening ability, confirming Crystal's research in 1997, which revealed that the students performed better in listening tests when they were allowed to use the combination of visual and graphic (MCALL) programs. This also shows that the use of visual media to assist listening comprehension is conducive to the improvement of students' listening performance.

According to Hooshang Khoshsima and Zahra Mozakka's research (2017), CALL can encourage the improvement of language skills, which can promote more learning. CALL has the potential to develop learners' language skills, including listening comprehension. At the same time, computer applications can help students learn a language, and they can be used to review and strengthen what they have learned in the classroom at any time and anywhere which also includes listening comprehension.

In short, CALL is able to provide students with some visual stimulation (such as MCALL) to assist their listening comprehension so that they can perform better on the listening test. This also illustrates another advantage of CALL in that it provides a variety of sensory stimulation to reinforce and strengthen students' learning in a way that cannot be done in a traditional classroom with only the teacher's teaching. 


\subsubsection{Reading}

In order to explore whether CALL can bring a positive impact on students' reading comprehension ability, Mehdi Yaghoobi and Seyyed Ayatollah Razmjoo (2016) have found that computer-assisted instruction has a positive effect on reading, and English learners can learn a language better through CAI. They also found that learning in a relaxed and pleasant atmosphere can help learners use problem-solving learning strategies. At the same time, Mehdi Yaghoobi and Seyed Ayatollah Razmjoo hold a positive attitude that CALL can stimulate students' learning and increase their learning motivation.

Taj, Ali, Sipra and Ahmad (2017) also believed that the use of computers and various online learning software can help students overcome learning problems related to anxiety and facilitate various online distance learning. At the same time, CALL has a positive effect on students' vocabulary acquisition and reading comprehension ability. However, influenced by Saudi Arabia's gender segregation laws, the results show that there is no significant difference when the participants are trained in the computer-aided environment alone, but there are differences when they are tested in non-gender groups.

In fact, not only do these two studies demonstrate the effectiveness of CALL in promoting students' reading comprehension, but they also demonstrate that CALL does help students learn in a relaxed atmosphere and better apply the learning strategies they have mastered.

\subsubsection{Writing}

According to whether the computer can have a positive impact on students' learning effect in the writing class, scholars' opinions are divided into two groups, one group thinks that the computer has a positive impact on students' writing effect, the other group thinks that the computer will have a negative effect on students' writing skills. A. ZAINI \& G. Mazdayasna (2015) used Microsoft Word office as a tool. The research results support the early research, that is, when students write on the screen, the quality of their articles is better than that of using pen and paper.

At the same time, the author also found that providing an appropriate writing environment and guiding skilled users can be very conducive to generating high-quality and longer writing tasks.

Naimeh's research in 2017 showed that CALL has a positive effect on students' writing quality. In addition, they also found that multimedia programs combined with speech recognition software can make students immerse in rich language practice environment. And since the computer is capable of playing so many different roles in and out of class, it is believed to be the most exciting and potentially useful aid so far available to language teachers and learners.

Hajimaghsoodi and Maftoon (2020) linked CALL with activity theory (AT) to explore its impact on learners' L2 writing performance. Under the guidance of AT, this paper studies the performance of computer-assisted language teaching in students' writing. The results show that CALL based on AT significantly improves Iranian English learners' writing skills. They also found that such a teaching method can significantly improve students' interest and enthusiasm. Because of the social and cultural nature of AT, CALL as a teaching method within the framework of AT, can promote cooperation and interaction inside and outside of the classroom. Based on the collaborative and negotiated nature of AT-based CALL, the learners were highly involved in the writing process.

In terms of writing, researchers agree that CALL not only provides electronic tools to improve students' writing efficiency, but also allows students to learn writing skills in an immersive, near-natural language environment through multimedia software.

\subsubsection{Overall Acquisition}

Among the 15 literatures selected by the author, four are concerned with the influence of CALL on students' final scores, among which Alotumi (2018) studies the influence of CALL on students' TOEFL scores. However, in the stage of raising questions, the author also adopts the division form of overall scores and specific scores. The research finds that compared with the traditional TBLT teaching mode, CALL can indeed play a significant role in promoting students' second language acquisition performance, and also has a positive impact on various special scores (iBT, reading, listening, speaking and writing) in TOEFL test.

According to the research results of Al-Nafisah in 2015, there were significant differences between the English scores of the control group and the experimental group. However, since the scores of the control group have no statistical significance, the improvement of the experimental group may be due to the different teaching methods of teachers and the combined effect of CALL. The CALL procedure plays a positive role in improving students' understanding of the components of the course. Strengthen the students' desire to learn English; It is more novel 
and interesting than traditional methods, which can motivate students to learn English through computers laterally and provide them with immediate feedback, which is of great benefit to students.

According to Omari's (2015) research results, the CALL can significantly enhance learning Arabic, according to the status quo of Arab foreign language teaching at the same time, the author also gives the corresponding suggestions: (1) The teaching of Arabic can no longer be taught through a discrete skills approach or through the textbook alone. Listening, speaking, reading, and writing are interconnected, and the textbook by itself is often not enough for learning or using diverse skills. (2) Arabic language teachers need to receive some guidance and training in order to constantly update their teaching skills and knowledge as teachers. As Al-Batal (2006) reports, a significant proportion of Arabic instructors lack training in foreign-language teaching because few opportunities for training and/or certification in Arabic teaching were available before the beginning of the 21st Century. Omari further suggested that the sample size should be appropriately expanded in future studies to avoid subjective factors affecting the experimental results.

Ikonta and Ugonna (2015) used a CALL software called Rosetta Stone to test whether it can improve students' academic performance. The results showed that Rosetta Stone has significantly improved students' communication level and language ability. At the same time, the students' listening, speaking, reading, writing and comprehensive skills also showed obvious differences in the results of the pre-test and post-test, indicating that Rosetta Stone has a significant effect on the improvement of students' comprehensive skills. In addition, Ikonta and Ugonna also pointed out the limitations of this study was limited to 35 students of one department in a university in Nigeria, which is not representative, besides, Rosetta Stone cannot represent all CALL software, so future research is needed to investigate the effects of other CALL software packages, while a larger sample in other contexts could also be used for similar studies.

The study found that CALL is more novel and interesting to motivate students and increase their willingness to learn English through the computer side. At the same time, however, the researchers suggest that a major problem is that some teachers are not yet aware of the importance of multimedia tools in the language classroom and still need training in the theory and application of computers.

\subsection{Advantages and Limitations of CALL}

\subsubsection{Advantages of CALL}

In fact, the widespread use of CALL in modern classrooms is closely related to its own advantages. Al-Nafisah (2015) mentioned in his study that CALL has many advantages:(1) It motivates introverted and shy students and makes them feel stress-free in a student-centered environment, which perfectly bypasses the traditional This perfectly bypasses the disadvantages of traditional teaching methods, helps protect their self-esteem, and enriches their language knowledge. (2) Computers can provide personalized contexts and interactive learning environments that allow students to enter a relatively natural second language acquisition environment. (3) Learners can use colors, graphics, drawings, and TV screens (AlAbdelHalim, 2009) to make visual input and enhance memory. (4) CALL programs can facilitate content analysis, topic perception, keyword recognition, syntactic categories, and the process of converting printed language into communicative language (Wright, 2003). (5) Using technology in and out of the classroom tends to make the classroom more interesting, and there is no doubt that CALL can promote student motivation (Jonita, 2002). (6) Using CALL enables students to be given the same information repeatedly so that they can practice it as many times as possible for better comprehension, and they can refer to the learning materials at any time and place with just a snap of their fingers.

In their 2018 study, Nejati, Jahangiri and Salehi mentioned that when computer technologies are combined with traditional second language classroom learning, students can learn more independently and teachers then have more time to focus on those parts of second language instruction that are still difficult or impossible to be processed by computers.

Omari (2015) argues that by using CALL in the classroom, teachers can focus on improving students' second language skills through the use of multiple technologies and provide diverse learning opportunities.

\subsubsection{Limitations of CALL}

CALL is not perfect, and Khalid Ibrahim Al-Nafisah (2015) argued that the reliability and validity of CALL as a tool to aid or supplement language learning in the classroom has not been fully substantiated. Because of the nature of CALL itself, controlling for all variables in an empirical study is not possible. Second, a common problem in such studies is that the sample size is small or limited to students of certain majors in one school, and reliability and validity are not guaranteed. (Taj et al., 2017) Similarly, one of the most realistic drawbacks is that teachers in certain areas have not been adequately trained in the use of CALL as suggested by Omari. The most 
realistic disadvantage is that teachers in some areas have not been adequately trained in the use of CALL, they have limited knowledge about the technology, and computer and multimedia technology requires a large financial investment that some areas cannot guarantee they have enough funds to support the local government's investment in this expenditure.

And without careful selection and organization of materials, careful planning and management of lessons, and training of students and teachers in their use, computers are useless. Therefore, teachers play an important role in implementing computers into the reality of classroom teaching. (Naimeh, 2017) That is why Hanson-Smith and Rilling (2014) claim that technology in education begins and ends with the teacher, that is, if the teacher is not interested in computers and this teaching tool, students will not be interested in learning the language within this framework.

\subsection{Artificial Teaching and Computer Teaching}

Since the appearance of CALL, the most controversial issue is teacher role positioning and computer role positioning, which is also a hot field in academia. Ikonta and Ugonna (2015) mentioned that CALL technology does not replace the role of teachers, but makes teachers more indispensable. The role of the teacher in the classroom is no longer just the transfer and teaching of knowledge, but similar to the guidance or examiner of students' independent learning. Al-Nafisah (2015) also believed that the emergence of CALL technology is intended to supplement, rather than replace, face-to-face classroom teaching.

Also, without careful selection and organization of materials, careful planning and management of lessons, and training of students and teachers in their use, computers are useless. Therefore, teachers play an important role in implementing computers into real classroom teaching. (Naimeh, 2017) That is why Hanson-Smith and Rilling (2014) claimed that technology in education begins and ends with the teacher, that is, if the teacher is not interested in computers and this teaching tool, students will not be interested in learning the language within this framework.

\section{Conclusion}

\subsection{Current Situation}

Research proves that CALL can indeed have a positive effect on students' English proficiency, and it is imperative for teachers to enhance their understanding of computer technology, as most of them still have a superficial grasp of the technology and should be proactive in accepting new things so as to guide learners to view CALL properly.

The Internet is gradually penetrating all aspects of our life, and more and more people are devoting fragmented time to the use of smartphones and social networks than to computers. With this in mind, we advocate the integration of language learning with the use of smartphones and social networks. While the positive impact of smartphones on students' language skills has yet to be studied, social networks do allow students to communicate at a high frequency, especially with the emergence of transnational social networking platforms which allow people to communicate effectively with native speakers of the target language through the screen, but teachers and parents still need to be aware of reminding learners to screen information and protect their privacy.

\subsection{Suggestions}

This review takes as its topic the impact of CALL on students' abilities in various aspects of language, and the author has the following suggestions on how to better apply CALL into classroom practice in second language teaching.

First, all kinds of schools, especially high schools should set higher working standards, hire well-trained teachers, train teachers for computer technology, increase the training of teachers for computer-assisted foreign language teaching, and provide realistic and specific support and guidance for teachers; combine computer network courses with the course syllabus and test evaluation, promote learning by examinations, give full play to the positive effect of examinations, and optimize teaching results.

Second, the government should increase support and funding to equip students with more advanced teaching aids and improve the necessary hardware equipment.

Third, teachers should first of all treat computer-assisted learning with a correct attitude, find their own role, although the teaching process should be "student-centered", but also appropriate guidance and supervision, to avoid some students who do not have strong self-control because of computer technology distracting; Secondly, teachers should find the best entry point in the classroom, clarify the syllabus and content before the class, and make sure that they are on target so that they can follow the instructions and grasp the rhythm of the class, but 
also make the best use of computers and the Internet to support teaching, show their advantages, motivate students, and improve the efficiency of the class. Finally, take full advantage of the computer, use rich Internet resources to provide students with appropriate language input, use PPT to give students visual stimulation, and also use social media and websites to stimulate students' sense of self-learning.

Fourth, students should be more aware of the need to use computer-assisted language learning in order to stimulate their enthusiasm and motivation for a second language and to increase their sense of autonomy in learning.

Fifth, the Internet is a double-edged sword, whatever has its both advantages and disadvantages, especially for students who have not fully established their value, too much exposure to the Internet too early may have a negative impact on them. Therefore, we advocate that teachers and students make good use of the Internet, maintain a rigorous attitude toward learning in the process of using it, and try to identify and avoid some online content that may bring negative effects.

\subsection{Future Trends}

In the future, researchers can focus on how to bridge the gap between students' language learning and technology use during and after school. Using informal fragments of time for language learning can many times have a subtle effect. Although many software development engineers have attempted to combine vocabulary memorization with computer games, they have not actually gained much traction with students, especially since parents still consider computers and cell phones off-limits, so we can look into this area of research to explore the impact of CALL on after-school facilitation.

\section{References}

Abbasian, G. R., \& Movahedfar, S. (2016). The Effect of Multimedia Computer Assisted Language Learning (MCALL) on Iranian EFL Learners' L2 Listening Comprehension. Journal of Applied Linguistics and Language Research, 3(6), 23-29.

Afshar Naimeh. (2017). COMPUTER-ASSISTED LANGUAGE LEARNING: THE EFFECT OF CALL ON IRANIAN EFL LEARNERS WRITING PERFORMANCE. International Scientific Journal, 4(48), 57-63. https://doi.org/10.15863/TAS.2017.04.48.9

Celce-Murcia, M., Brinton, D. M., \& Goodwin, J. M. (1996). Teaching Pronunciation: a reference for teachers of English to speakers of other languages. New York, NY: Cambridge University Press.

Cellat, S. (2008). Computer assisted vocabulary learning: a study with Turkish 4th grade EFL learners (Unpublished Master Thesis). Anadolu University, Eskisehir, Turkey.

Crystal, D. (1997). English as a global language. Cambridge: Cambridge University Press.

Davies, G., \& Hewer, S. (2011). Introduction to new technologies and how they can contribute to language learning and teaching. In G. Davies (Ed.), Information and Communications Technology for Language Teachers (ICT4LT). Retrieved from https://www.ict4lt.org/en/en_mod1-1.htm

Hajimaghsoodi, A., \& Maftoon, P. (2020). The effect of activity theory-based computer-assisted language learning on efl learners' writing achievement. Language Teaching Research Quarterly, 16, 1-21. https://doi.org/10.32038/ltrq.2020.16.01

Halim, A. A., Smadi, A. Q., \& Oqlah. (2009). Designing a computer - assisted language learning program (call) and measuring its effect on jordanian secondary school students ' reading comprehension in english.

Harasim, L. (2012). Learning Theory and Online Technologies (2nd ed.). New York: Routledge. https://doi.org/10.4324/9780203846933

Ikonta, N. R., \& Ugonna, N. C. (2015). The effect of rosetta stone (computer-assisted language learning) software on english as second language students' proficiency in english language. African Educational Research Journal.

Imtiaz, H. T., Fatimah, A., Muhammad Aslam, S., \& Waqar, A. (2017). Effect of technology enhanced language learning on efl reading comprehension at tertiary level. Arab World English Journal, 8(1), 108-129. https://doi.org/10.24093/awej/vol8no1.9

Khalid, I., \& Al-Nafisah. (2015, July). Designing a Computer-assisted Language Learning (CALL) Program and Measuring its Effect on Saudi EFL Learner's Achievement in English. 
Khoshsima, H., \& Mozaka, Z. (2017). The effect of computer-assisted language learning (call) on the iranian upper-intermediate efl learners' listening skill. Journal of Applied Lingus \& Language Research, 4(2), 81-91.

Krashen, S. (1982). Principles and practices of second language acquisition. Oxford, UK: Pergamon Press.

McCarthy. (1988). Vocabulary and language teaching. New York, NY: Longman.

Mohialdeen, \& Alotumi. (2018). The effect of call-based instruction on students' score attainment on the toefl ibt in a yemeni context. International Journal of Computer Assisted Language Learning \& Teaching. https://doi.org/10.2139/ssrn.3314717

Muindi, M. N., \& Ong'onda,N. A.(2016). Computer Assisted Language Learning Software: The Effect of Integrating Computer Assisted Pronunciation Training on Kenyan English Phonetics Class at the University Level. International Journal of Academic Research in Progressive Education and Development, 5(4), 1-21.

Nejati, E., Jahangiri, A., \& Salehi, M. R. (2018). The effect of using computer-assisted language learning (call) on iranian efl learners' vocabulary learning: an experimental study. https://doi.org/10.18844/cjes.v13i2.752

Omari, \& El, S. (2015). The effect of computer-assisted language learning on improving arabic as a foreign language (afl) in higher education in the united states. Procedia - Social and Behavioral Sciences, 192, 621-628. https://doi.org/10.1016/j.sbspro.2015.06.109

Pennington, M. C., \& Zegarac, V. (1998). What is pragmatic transfer? Conference of the International Pragmatics Association, Reims, France.

Rahnavard, F., \& Heidar, D. M. (2017). The impact of computer - assisted language learning (call) /web-based instruction on improving efl learners' pronunciation ability. International Journal of Research in English Education, 2(1). https://doi.org/10.18869/acadpub.ijree.2.1.49

Richards, J. C., \& Schmidt, R. (2010). Longman Dictionary of Language Teaching and Applied Linguistics (4th ed). Britain: Pearson Education Limited.

Sedaghatkar, M. (2017). The effect of computer-assisted language learning (call) on immediate and delayed retention of vocabularies in general english course. International Journal of Applied Lingus \& English Literature, 7(1), 231. https://doi.org/10.7575/aiac.ijalel.v.7n.1p.231

Yaghoobi, M., \& Razmjoo, S. A. (2016). The potentiality of computer-assisted instruction towards ameliorating iranian efl learners' reading level. Computers in Human Behavior, 59, 108-114. https://doi.org/10.1016/j.chb.2016.01.033

Zaini, A., \& Mazdayasna, G. (2015). The impact of computer-based instruction on the development of efl learners' writing skills. Journal of Computer Assisted Learning, 31(6), 516-528. https://doi.org/10.1111/jcal.12100

\section{Copyrights}

Copyright for this article is retained by the author(s), with first publication rights granted to the journal.

This is an open-access article distributed under the terms and conditions of the Creative Commons Attribution license (http://creativecommons.org/licenses/by/4.0/). 